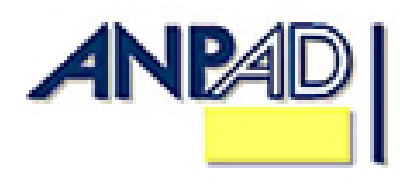

Available online at http://www.anpad.org.br/bar

BAR, Rio de Janeiro, v. 11, n. 1, art. 3, pp. 47-63, Jan./Mar. 2014

\title{
Leadership, Personal Values, and Cultural Context in Brazil, China, and the USA
}




\begin{abstract}
This research examines the association between configurations of personal values and managerial incumbency among professionals in Brazil, the US, and Asia. Our research is different from classical leadership research as well as most cross-cultural studies in that it focuses on variance within countries first and then compares results between countries, while the great bulk of research looks at differences between means from one country or category to another. Accordingly, we use cluster analyses rather than analyses of variance or regressions as the major analytical tool. By generating comparable clusters of professionals in different countries, we obtain a novel view of the relationship between individual variables, cultural settings, and leadership. In each cultural setting sampled there is one cluster of personal values which is highly associated with managerial position, and particularly with upper management. These managerial clusters are similar in their overall profile, and are the smallest clusters in each of the three countries, suggesting a universalistic managerial personality like that identified by Miner over thirty years ago. At the same time, we find significant differences between countries in the absolute numerical levels of values held by managers and even greater differences in the levels of values which characterize their subordinates.
\end{abstract}

Key words: leadership; culture; comparative management. 


\section{Introduction}

Are leaders different from their followers? This deceptively simple question has been the source of much debate over more than a century and is still incompletely resolved. One of the earliest and most influential theories, Carslyle's (1841) great man theory of leadership, argues that great leaders are vastly different in views and attributes from the general population. Over time this view was challenged and some began to view leadership as more of a democratic expression of historical processes (Keegan, 1987, Spencer, 1896; Yukul, 2006). After an influential paper by Stogdill (1948) in the late 1940s, the search for essential, durable differences between leaders and followers fell into disrepute. Recently leadership studies have become interested in leader-follower differences again (Zaccaro, 2007), so debate around this basic question has taken yet another turn.

If the question of differences between leaders and their colleagues has been incompletely resolved in general, the question, "are leaders and their followers different in different countries and cultures" has as yet received little empirical attention (House, Hanges, Javidan, Dorfman, \& Gupta, 2004, pp. 661-673). Considerable evidence exists that there are both similarities and differences across countries in the kinds of behaviors sought for in ideal leaders, but actual empirical studies of differences between leaders and followers are, to our knowledge, rare or nonexistent. In this paper, we undertake a modest empirical study of this question among business professionals in Chinese Asia, Brazil, and the United States. By employing a methodology and instruments different from former studies, we conclude that there are indeed substantial differences between professionals who occupy formal leadership positions and their peers. Moreover, we discover that those who occupy formal supervisory roles belong to a small minority in all three cultural settings. Specifically those professionals who have supervisory responsibilities belong to small clusters which value abstraction, planning, and flexibility much more than their colleagues and value affection and loyalty much less. These profiles are less than $20 \%$ of our sample for all three cultural settings studied. We also observe that there are significant similarities and differences in cluster sizes and configurations of personal value profiles across the three national samples in our study.

\section{Theoretical Background and Study Contribution}

The research question posed above runs parallel to important themes that have permeated leadership studies. A large amount of the leadership literature and research of the past century can be summarized as belonging to three strands: trait, behavioral or contingency (A. D. S. Sant'Anna, Nelson, Campos, \& Leonel, 2010; Yukul, 2006; Zaccaro, 2007). Although recently these three strands have seen efforts at integration and dialogue, they are intellectually distinct, and all three have historically focused their research efforts in the U.S. and Northern Europe. Trait theory, which grew out of the great man approach mentioned above, is based on the idea that leaders possess certain attributes or traits which permit them to attract, secure and control followers. A long period of research and theorizing running from the mid-1800s through the first half of the 1900s developed this idea. The trait approach passed out of favor from the 1950s for most of the rest of the century. However, after the year 2000, trait theories have made a comeback, especially because of the success and comparative stability of the big five theories and measures of personality. Personality theory, which was quite dispersed for most of the 20th century, gained a degree of consensus around the traits of agreeableness, conscientiousness, openness to experience, extroversion, and neuroticism (Digman, 1990) and subsequently studies of the relationship between the big five and different leadership facets have flourished. Primarily using these five measures, credible research has indicated that stable psychological traits and demographic variables such as gender share a modest but consistent association with the occupation of formal leadership positions in organizations (Derue, Nahrgang, Wellman, \& Humphrey, 2011; Foti \& Hauenstein, 2007; Judge, Bono, Ilies, \& Gerhardt, 2002; Ng, Ang, \& Chan, 2008; Zaccaro, 2007). 
Behavioral theories of leadership arose in response to the predominance of trait theories and argued that people of great personal and psychological diversity have successfully played leadership roles, but these diverse people have exhibited common sets of actual behaviors (A. D. S. Sant'Anna et al., 2010; Yukul, 2006). The dominant behaviors in the classic behavioral studies were an emphasis on task and an emphasis on relationship, present in varying mixtures. More recently however, two new and more complex behaviors have become fashionable in research. Recently, transactional and transformational leadership behaviors are the most frequently studied, with charismatic leader behaviors also receiving considerable attention. Transactional leadership behaviors focus on negotiating compliance behaviors with subordinates using incentives and punishments. At its base, transactional leadership elicits rationally oriented behaviors, using the logic of economic exchange. Transformational leader behaviors are more emotionally, ideologically and identity charged. They contain four thrusts: idealized influence, inspirational motivation, intellectual stimulus, and individualized consideration (Bass, 1985; Seltzer \& Bass, 1990). A large body of research has surfaced in recent years, especially around transformational leader behaviors.

The contingency approach to leadership tends to integrate one or both of the trait and behavioral streams. The basic argument behind contingency theories is that the setting within which leadership is practiced mediates or determines the impacts of different traits or behaviors. The dominant contingency theories developed during the second half of the $20^{\text {th }}$ century used task versus relationship leader behaviors as their major inputs. Hersey, Blanchard and Johnson's (1996), Fiedler's (1964) contingency theories were the major works. Hersey, Blanchard and Johnson argued that the maturity of the subordinate group conditioned the effectiveness of different styles. With low maturity subordinates or groups, the most appropriate style is directive, while at high levels of maturity benign neglect, or delegation is best. In the middle range of maturity, mixtures of the two extremes are most effective. Leaders should alter their styles to match the maturity of their followers. Fiedler proposed a model with some commonalities, but he emphasized the job setting to a greater degree and did not make any assumptions about the ability of leaders to alter their styles. In this regard, Fiedler is more consistent with trait theories because he views leadership styles as more or less invariant. House's (1971) theory, the most mature contingency model to date, included more contingencies so that a potential leader must diagnose up to 16 different combinations of contingency variables in order to choose an appropriate leadership style.

Given the relative sophistication and complexity of the contingency theories of leadership developed during the 1970-90s, it is somewhat surprising that national culture does not surface as a prominent contingency to be dealt with in mainline leadership studies (Tsui, Nifadkar, \& Ou, 2007). Already in the 1970s and early 1980s debates about the degree to which organizational structures are invariant across national settings were common (Boyer, 1996; Guillen, 2001; Hickson \& MacMillian, 1981), but with the exception of Birnbaum, and Wong's (1985) classic work arguing that preferred management styles in Hong Kong were similar to those in the USA, and Bass' (1998) argument that transformational leadership works in most national settings, there was little research on the relationship between leadership and cultural context until fairly recently. The quantitative research originating in Brazil is no exception. Most of the quantitative studies we were able to locate tend to validate instruments or theories for Brazil with few adaptations, or tend to relate leadership style to dependent variables of interest, such as employee performance, commitment, or the like (see for example Abbade \& Brenner, 2009; Fonseca, Porto, \& Barroso, 2012; Gimenez \& Inácio, 2006; L. L. Sant'anna, Paschoal, \& Gosendo, 2012; Oliveira, Sant'Anna, \& Vaz, 2010).

Brazilian qualitative studies and essays on leadership are much more culturally aware and generally more critical of the applicability of foreign scholarship (A. D. S. Sant'Anna et al., 2010; A. M. Carvalho, 2010; A. M. Carvalho, Tanure, Santos, \& Lima, 2012; Davel \& Machado, 2001; Oliveira et al., 2010) but they are typically limited to theoretical exercises or case studies. 


\section{National culture as a leadership contingency}

From the early 1990s up to the present, Robert house and a group of over 100 collaborators worldwide have undertaken an ambitious and extensive effort to catalogue preferred leader behaviors worldwide (See Ashkanasy \& Roberts, 2010; Grachev \& Bobina, 2006; House, Javidan, Hanges, Dorfman, 2002; Javidan \& Carl, 2005; Muczyk \& Holt, 2008 for just a few representative publications). The GLOBE studies, spanning 61 countries and including 17,000 respondents, indicate that there is a core of desired and undesired leader behaviors that varies minimally by nation, in addition to a loose set of behaviors that vary substantially from one culture to another. The evidently stable factors which favor effective leadership behaviors are integrity, foresight, encouragement, and communication. Negative attributes which impede leadership are self-protection, noncooperation, and autocracy. Attributes which vary by culture are individualism, status consciousness and risk taking. Although the contingent factors vary broadly, individualism and risk taking seem to be more acceptable in Anglo and Nordic countries, while status consciousness is more prominent in other regions.

The GLOBE studies are of great interest and are groundbreaking in many ways. However, precisely because of their attempts to collect massive amounts of data, they have excluded a number of important analytical and empirical issues which are easier to address in a smaller study. The present research attempts to explore some of these issues with a modest empirical study using data from Brazil, the US and Chinese Asia. Our central research objective is to determine whether the personal values of professionals occupying positions of formal leadership are different from their peers in the three cultural settings studied. By undertaking this different focus, we provide a link between trait and contingency approaches to leadership which has not, to our knowledge, been attempted in crosscultural studies of leadership, despite efforts to do so in North American studies (Derue et al., 2011; Foti \& Hauenstein, 2007; Ng et al., 2008). A secondary but closely related concern is the degree to which the clusters of personal values held by professionals in these countries are similar to one another in size and configuration. These concerns are important conceptually and in practical terms because the degree to which ecologies of personal values vary across cultural settings is likely to impact the degree to which organizational and managerial practices can be successfully implemented without adaptation as one moves from one country to another. There are three important enhancements in our data set which permit us to approach this research agenda in a manner that goes beyond what is found in the GLOBE studies:

1. We focus on personal rather than collective values.

2. We study the relationship between personal values and formal leadership position across societies.

3. We study variance within personal values across societies using cluster analysis.

\section{Justification for current study}

Below we expand on the three contributions outlined above. Consistent with their emphasis on national culture, the GLOBE studies and the Hofstede (1980) studies which preceded them asked questionnaire respondents general questions about what is desirable or valuable. Hence questions were phrased in general terms like A leader should command respect, or Subordinates should not challenge their boss. These types of questions are useful for identifying societal values or desired leader behaviors. However, they do not identify what the individuals in the sample value personally. Because leaders by role and personality often stand out from those around them, it is of considerable importance to study the relationship between leadership incumbency and individuals' values. In this sense, our work extends the current resurgence in trait theory to the cross-cultural study of leadership. At the same time, our emphasis on individuals' values rather than dimensions of their personality (which are known to vary more by genetics and less by culture than do personal values - see Roccas, Sagiv, Schwartz, \& Knafo, 2002) permit us to examine personal dimensions which are more likely to vary across nations. 
The Globe studies do not consider differences between managers and non-managers. All respondents hold managerial positions. They therefore provide a guide to managerial perceptions of ideal behaviors, but are silent regarding differences between managers and non-managers. Our sample contains college-educated professionals in capitalist organizations, of which only a proportion have direct subordinates. Hence we are able to examine differences in the values of professionals who have attained formal positions of leadership versus those who have not. Not only is this distinction conceptually interesting, it has considerable practical value for those interested in selecting potential managers. In other words, our study provides predictive validity of the relationship between personal values, culture, and formal leadership.

Cross-cultural studies generally, and studies of leadership particularly, focus on general differences between nations, neglecting differences within nations (Tsui et al., 2007). The GLOBE studies are the primary focus of contrast here, but other classic studies follow this pattern. For example Hofstede's (1980) classic studies of IBM employees in over 40 countries, Schwartz's studies of school students and teachers' values, and Hampden-Turner and Trompenarrs' (1993) studies of worker values emphasized the differences in the statistical averages found between countries without considering possible differences in the subcategories or clusters of different values that may exist within countries (Schwartz, 1999; Schwartz \& Bardi, 2001). Other cross-cultural studies follow the same pattern of considering heterogeneity across cultures without studying differences within cultures. Hence while we know that Indians hold different perceptions and values from Brazilians, we know nothing about the degree to which the different value profiles held by persons within India follow similar or different patterns from those held by Brazilians. In making this argument we have no intention to diminish value of existing research or question the existence of main effects across countries. We seek only to provide a more complete view of similarities and differences across cultures.

\section{Methodology sample and instrument}

As we stressed above, we proposed to approach our research question differently from the bulk of cross-cultural and leadership studies and for this reason our methodology is also different. Most studies to date have sought to identify differences in mean levels of attitudes, values or practices from one cultural setting to another. The statistical models associated with this approach are typically analysis of variance, linear regression or some variant thereof. These techniques seek to measure overall levels of a variable in one setting in contrast to another while controlling for the amount of dispersion or variance in samples. In an ANOVA, if the distance between means is greater than a statistically significant degree of variance within the samples, a genuine or significant difference is said to exist. In the contrary case, it is assumed that any differences between samples have come about as a function of random error. Similarly, if linear regression is the model, the size of association or slope of the curve generated by the association between variables is large compared to the unaccounted for variance observed, a significant difference is presumed to exist. When distributions are normal and variances are not great, these models work admirably. However, if one is interested in variation within samples, such models are not as useful. Consider a scenario from politics. It is well known that political opinion in the United States has become increasingly polarized over the years, especially since Barak Obama's election. As a result, while the means on a number of measures of conservatism or liberalism have remained more or less constant over time, the variance or extremity of opinions has increased dramatically such that there are fewer Americans at the political center and much more at the more extreme left and right. Thus, while there used to be a smooth range of opinion in U.S. politics, now there are two distinct and rather extreme types. By contrast, European politics have traditionally contained a greater range of subgroups including ultranationalists, green parties, and Christian democrats and well as syndicalist labor parties. If we contrast European and American politics using analyses of variance, Europe will appear more liberal politically than the US, but the comparative degree of variance and the richer diversity of types of European politics compared to US politics will be entirely lost. Measures which emphasize central tendency and assume moderate, random variance do not detect these differences adequately. In the case of personal values and leadership across countries, we have no theoretical precedents to suggest how much dispersion or how many types of value configuration exist, so traditional linear and central tendency models which rely 
on priori specification of relationships and associations are not the best choice. Cluster analysis techniques, which catalogue patterns of variance in a sample are the most logical starting point (Kerlinger \& Lee, 2000).

In order to capture the dynamics of variance in a situation, techniques like cluster analysis are much more revealing. Cluster analysis is a less positivistic methodology because it seeks to empirically describe regularities across variables while identifying pockets or clusters or regularities of similar perceptions held by actors within the sample (L. F. Carvalho \& Vergara, 2002). It makes no assumptions about equality or degree of variance in the system, instead mapping patterns of variance within the sample. By performing the same cluster analysis on each of our national samples we are able to see whether the different types of value profiles that exist in different countries are larger or smaller, or follow similar of different configurations. This results in a much richer description than standard analysis of variance or linear models would permit, and for this reason is a useful technique when performing this type of exploratory research.

Cluster analysis or other exploratory techniques are especially indicated if we admit the possibility that more than one value profile is associated with leadership. If for instance, as the contingency theories of leadership have long affirmed, successful leaders may exhibit either task or relationship behaviors depending on the setting, then a cross-cultural study comparing means of task and relationship orientation is likely to be misleading or reveal nothing while a cluster analysis of task and relationship behaviors might reveal that in one country a small cluster of persons which exhibit a high incidence of task behaviors occupy leadership positions, while in another country there is a large cluster of persons high in both task and relationship behaviors which occupy leadership positions. The likelihood that clusters of variables will be predictive of leadership position increases to the degree that a greater number of variables is included. For instance if in a given country there is a small cluster of task oriented females, with high emotional intelligence, and high seniority, which occupy a majority of formal leadership positions, traditional linear techniques are unlikely to detect the relationship while cluster analysis will.

\section{Instrument}

We used Nelson's Personal Value Profile to collect self reports of personal values from professionals in Brazil, the United States, and ethnic Chinese from Taiwan, Hong Kong, and Singapore - all capitalist states dominated by Chinese culture. Our sample consisted of 734 salaried, college degree holders from 46 different organizations. Of this sample, 212 held middle or upper-level management positions with at least 5 direct subordinates. 341 of our sample were ethnic Chinese from Hong Kong, Singapore, or Taiwan, 210 were from the United States and 183 were from Brazil. Although the samples were not randomly drawn, we were careful to include professionals from organizations of roughly comparable size and type in all three samples. Respondents were from manufacturing, financial, and other service business with an average size of 125.4 employees and a standard deviation of 98 . There were no significant differences between the samples on these parameters. The public sector was not represented in our sample.

The PVP is part of a suite of three instruments using the same variables to measure personal values, perceived organizational values, and desired organizational values. (In this research only responses to questions about personal values are reported.) Like the classic leadership studies, the PVP instrument contains a Task or Work Quadrant, and a Relations or Concern for Persons quadrant, each with four sub-dimensions. The work quadrant contains sub-dimensions regarding Hard Work, Time, Finish Task, and Quality. The Relations Quadrant contains Affect, Empathy, Sociability or group orientation, and Loyalty. Two other quadrants, Control and Thought are less dependent on traditional American management thought and were informed by an extensive survey of anthropological and sociological literatures (see Nelson, 1997, 2011; Nelson \& Gopalan, 2003; Nelson \& Loureiro, 1996 for more theoretical detail). Within each of these four general domains, four subthemes are proposed that frequently are in states of tension with one another, similar to the general dimensions of Work, Relations, Control, and Thought. The four sub-dimensions of the Work Quadrant are Effort (hard 
work), Time (deadlines, speed), Complete Task, and Quality. As an example of tensions between subdimensions, Time and Finishing Task are frequently seen as detrimental to quality (haste makes waste). The relations Quadrant contains Affect, Empathy, Sociability, and Loyalty. These dimensions perhaps coexist more peacefully than other quadrants, but it is still common to find negative correlations between Sociability, Affect, and Loyalty, for instance. The Control quadrant contains Dominance, Status, Politics, and Leadership. The Thought Quadrant contains Abstraction, Planning, Exposition, and Flexibility. These too contain contradictions which are rendered especially clear by the ipsative nature of the instrument.

The Personal Value Profile attempts to measure its 16 variables by ranking 20 sets of four statements like I am a hard worker, I am loyal, I enjoy the uncertainties of life, and I am punctual. By forcing the respondent to assign $1^{\text {st }}, 2^{\text {nd }}, 3^{\text {rd }}$, and $4^{\text {th }}$ place to each statement in 20 unique sets, each of the sixteen dimensions appears in a ranking with each other dimension exactly once. The resulting response vector has a sum of 200 and each dimension receives 5 rankings from 1 to 4 , yielding scales that range from 5 to 20. Validations of and modest normative data for the AVP and PVP instruments have been undertaken in the US, Argentina, Brazil, India, and more recently for Hong Kong, Taiwan, and Singapore (www.c-vat.com).

The original PVP was simultaneously developed in both Brazilian Portuguese and English. The Mandarin Chinese version of the instrument was used only for 43 non-English speaking respondents in Taiwan. The other 298 ethnic Chinese responded to the English version of the instrument. The means and variances for both the English PVP and Mandarin PVP completed by ethnic Chinese were not significantly different.

The ipsative nature of the instrument precludes evaluation using traditional factor analytic techniques (Closs, 1996; Dunlap \& Cornwell, 1994) and inter-item reliabilities for scales must use monte carlo, or enumerative variance estimation, techniques to compensate for negative mean intercorrelations. Using alternative reliability computations, scale reliabilities vary from 0.6 to 0.9 . Test-retest reliabilities using a testing interval of one month have proven acceptable, ranging from 0.6 to 0.9 with average correlations around 0.8. Reliability and validity studies of the Personal Value Profile and its partner instrument, the Aggregate Value Profile can be found in Nelson, Vasconcelos, Ponçano, and Pasqualini (2010), Nelson (1997, 2011), Nelson and Gopalan (2003), as can extensive justifications for the use of the instruments' ipsative nature and of cluster analyses to study organizational culture, executive turnover, personal values, and related topics. Extensive normative data for the PVP have been collected, particularly in Asia where over 60,000 PVPs have been administered.

\section{Analytical strategy}

We cluster our results in order to get an idea of the distribution of configurations of personal values in the particular organizational context and then consider the distribution of managerial roles between the clusters. This provides an idea of the social landscape within which leadership is being exercised and of the relative distribution of value orientations both within a given national as well as across national settings. It also permits a graphic, standardized comparison of differences between subgroups. In this paper, we use four clusters per cultural region. Although this choice is somewhat arbitrary, it is best maintained across the three sampled environments for comparative purposes.

In addition to the theoretically driven reasons for the use of cluster analysis described above, there are other methodological and epistemological motivations for its use in this setting. Given the exploratory and practical nature of our study, limited sample $(\mathrm{N})$ vis a vis the populations studied, and the absence of clear theoretical guidance for the formulation of formal hypotheses, it would be preferable to identify the underlying contours of our data set and interpret regularities post hoc rather than relying on the stronger inferential and statistical assumptions required by techniques which involve identification of independent and dependent variables and their associated causal assumptions (Glaser \& Strauss, 1967; Kerlinger \& Lee, 2000; L. F. Carvalho \& Vergara, 2002). Another practical, 
but not trivial reason is that the mechanical identification of clusters and subsequent interpretation of their meaning is much easier to understand and present within the space limitations of a paper like this, especially in the light of the multiple approaches, literatures and types of data used in studies involving multiple cultures and levels of analysis.

\section{Results}

A few results are immediately striking when we use clustering instead of main effects/interaction effects models to examine managerial incumbency in its international context. Others are less immediately obvious but perhaps equally significant. We first note that within the clusters of each of the three cultural groups is one small - indeed the smallest - grouping for each country that contains a similar profile. For Brazil, it is Cluster 3 with 15 percent of the respondents, for the USA it is Cluster 2 with 18 percent of respondents, and for the Ethnic Chinese it is Cluster 1 with 20 percent of the respondents. (See Tables 1, 2, and 3 respectively). Upon studying these clusters we note immediate similarities. For three out of four Work dimensions, each of these groups ( 3 for Brazil, 2 for the USA, and 1 for China) has the lowest means for its respective country. For the Leadership and Flexibility dimensions, each of these groups has the highest means for its respective country. For the Abstraction dimension, each group has the highest, or in the case of the USA, the second highest mean for its respective culture. In the relationship quadrant, the USA and the Chinese have the lowest or second lowest means for Affect, Empathy, and Loyalty, while Brazil has comparatively high Empathy and Loyalty means. Finally, we observe that each of these clusters is the only one in its country which contains a majority of managers: 22 out of 29 for Brazil, 29 out of 38 for the USA, and 52 out of 68 for the Chinese. Similarly, each cluster, again the smallest for its country, contains the largest proportion of managers of any of the four clusters: 52\% of all of the managers for Brazil, $36 \%$ percent of all the managers for the USA sample, and $57 \%$ for the Chinese. The statistical significance for these results is massive at less than 0.001 for all three cultures, and the magnitude of the association is large - Phi is 0.58 for the Brazilian and Chinese results and 0.50 for the U.S. result. Compared with other empirical studies of leadership and individual attributes, these results are expressive. Derue, Nahrgang, Wellman and Humphrey (2011) meta-analysis of 729 studies of leadership, traits and behaviors indicated that squared correlations between traits and leader effectiveness ranged from 2 to 22 percent. Recent trait studies in top international journals have results within these bounds ( $\mathrm{Ng}$ et al., 2008) Although our analyses do not accommodate the calculation of multiple correlations, the over $80 \%$ classification accuracy obtained from cross tabulations of formal leadership position with cluster membership suggests a predictive validity at least on par with the most successful studies to date.

Table 1

Cluster Centroids for Brazilian Professionals

\begin{tabular}{lcccc}
\cline { 2 - 5 } & \multicolumn{4}{c}{ Cluster } \\
\cline { 2 - 5 } & 1 & 2 & 3 & 4 \\
\hline Hard Work & 16.20 & 15.03 & 10.09 & 16.80 \\
Time & 13.87 & 14.86 & 8.55 & 11.40 \\
Finish Job & 10.47 & 13.07 & 10.73 & 13.85 \\
Good Work & 16.13 & 15.59 & 13.82 & 16.00 \\
Affect & 9.87 & 13.03 & 9.09 & 8.20 \\
\hline
\end{tabular}


Table 1 (continued)

\begin{tabular}{lcccc} 
& \multicolumn{3}{c}{ Cluster } \\
\cline { 2 - 5 } & 1 & 2 & 3 & 4 \\
\hline Empathy & 10.20 & 14.66 & 13.09 & 11.65 \\
Sociability & 13.40 & 14.72 & 16.00 & 13.30 \\
Loyalty & 13.33 & 16.62 & 15.36 & 14.95 \\
Dominance & 13.47 & 11.79 & 12.18 & 12.40 \\
Status & 10.53 & 9.38 & 8.45 & 8.85 \\
Politics & 12.07 & 9.83 & 13.18 & 9.70 \\
Leader & 15.53 & 10.83 & 16.00 & 11.65 \\
Abstraction & 8.80 & 9.45 & 12.82 & 12.40 \\
Plan-Org. & 14.07 & 10.90 & 14.45 & 13.95 \\
Exposition & 10.53 & 9.83 & 12.73 & 11.65 \\
Tol. Ambiguity & 11.53 & 10.41 & 13.45 & 13.25 \\
\hline Percentages & $\mathbf{2 0}$ & $\mathbf{3 9}$ & $\mathbf{1 5}$ & $\mathbf{2 7}$ \\
\hline
\end{tabular}

Note. Managers: 12, 3, 22, 5; Non-managers: 33, 62, 7, 39; Chi-squared $=61.96 \mathrm{df}=3 \mathrm{p}=.0000$.

Table 2

Cluster Centroids for U.S. Professionals

\begin{tabular}{lcccc} 
& \multicolumn{3}{c}{ Cluster } & \\
\cline { 2 - 5 } & 1 & 2 & 3 & 4 \\
\hline Hard Work & 15.05 & 11.16 & 15.85 & 14.08 \\
Time & 14.07 & 8.76 & 14.09 & 11.59 \\
Finish Job & 12.95 & 10.08 & 14.03 & 12.55 \\
Good Work & 16.77 & 14.50 & 17.23 & 15.02 \\
Affect & 11.84 & 10.84 & 9.05 & 15.89 \\
Empathy & 14.16 & 12.39 & 11.91 & 16.19 \\
Sociability & 10.65 & 11.55 & 10.11 & 12.64 \\
Loyalty & 16.58 & 13.71 & 13.63 & 17.00 \\
Dominance & 11.51 & 12.45 & 12.83 & 12.58 \\
Status & 10.60 & 11.50 & 11.25 & 13.19 \\
Politics & 6.93 & 11.05 & 7.89 & 8.14 \\
Leader & 9.19 & 14,79 & 13.00 & 11.28 \\
Abstraction & 14.93 & 14,50 & 11.29 & 10.08 \\
Plan-Org. & 13.44 & 13.87 & 15.05 & 11.08 \\
Exposition & 11.00 & 15.74 & 11.97 & 10.19 \\
Tol. Ambiguity & 10.33 & 13.11 & 10.83 & 8.52 \\
\hline Percentages & $\mathbf{2 0}$ & $\mathbf{1 8}$ & $\mathbf{3 1}$ & $\mathbf{3 1}$ \\
\hline Ne. Mang & & & &
\end{tabular}

Note. Managers: 10, 29, 34, 7; Non-managers: 32, 9, 31, 58; Chi-squared $=53.32 \mathrm{df}=3 \mathrm{p}=0000$.

BAR, Rio de Janeiro, v. 11, n. 1, art. 3, pp. 47-63, Jan./Mar. 2014 
Table 3

Cluster Centroids for Ethnic Chinese Professionals

\begin{tabular}{lcccc}
\cline { 2 - 5 } & \multicolumn{3}{c}{ Cluster } & \\
\cline { 2 - 5 } & 1 & 2 & 3 & 15.17 \\
\hline Hard Work & 11.68 & 15.52 & 12.91 & 11.83 \\
Time & 11.84 & 15.06 & 13.14 & 13.28 \\
Finish Job & 12.32 & 15.17 & 12.34 & 15.81 \\
Good Work & 16.25 & 17.59 & 15.51 & 15.34 \\
Affect & 9.38 & 10.64 & 13.62 & 15.56 \\
Empathy & 11.32 & 12.72 & 14.70 & 13.57 \\
Sociability & 12.57 & 11.27 & 15.57 & 17.07 \\
Loyalty & 12.21 & 14.92 & 14.71 & 11.51 \\
Dominance & 12.01 & 12.03 & 13.14 & 9.49 \\
Status & 10.72 & 10.92 & 13.28 & 8.89 \\
Politics & 10.76 & 8.73 & 8.66 & 8.19 \\
Leader & 13.78 & 9.63 & 10.53 & 12.88 \\
Abstraction & 14.03 & 12.70 & 11.74 & 12.06 \\
Plan-Org. & 15.29 & 13.93 & 11.49 & 9.86 \\
Exposition & 13.16 & 9.25 & 10.17 & 9.49 \\
Tol. Ambiguity & 12.66 & 9.94 & 8.50 & $\mathbf{2 6}$ \\
\hline Percentages & $\mathbf{2 0}$ & $\mathbf{3 2}$ & $\mathbf{2 2}$ &
\end{tabular}

Note. Managers: 52, 24, 9, 5; Non-managers: 16, 85, 67, 83; Chi-squared $=116.56 \mathrm{df}=3 \mathrm{p}=0000$.

These results supply resounding support for the idea that there is a managerial value set in capitalist organizations that transcends cultural and organizational boundaries. This idea is of course not new - in many ways it merely reaffirms the assertions of trait theorists (Miner, 1976) and indeed the intuitions of many if not most practicing managers. What we feel is new here, and would not have been discovered using traditional methodologies, is the comparative smallness of the managerial values group and the distance between their values and the values of the majority of their subordinates. Despite the fact that our sample contained only well-trained and paid professionals from corporations, in none of the three cultural settings did they make up more than $20 \%$ of the sample. Perhaps more importantly, in each country there are large clusters of professionals whose personal values are starkly different from those of the managerial cluster. Indeed, the managerial cluster holds some values which no other group favors. The mean for the USA managerial cluster on Work is 11.16 while the other group means are 15.85, 15.65, and 14.08. For Time, it is 8.76 while for the other groups the means are 14.07, 14.09, and 11.59. For Exposition, it is 15.74 versus 11.0, 10.19, and 11.97. This tendency is amplified for Brazil and literally doubled for the Chinese sample. For the Brazilian sample, there are 5 values that follow this pattern: Hard Work, Time, Quality, Sociability and Exposition. The Chinese sample is yet more extreme with 7 of 16 values: Hard Work, Loyalty, Politics, Leadership, Abstraction, Exposition and Flexibility.

There is a second cluster in each country sample which contains a substantial number of managers although nothing like the high proportions of management found in the small managerial cluster. Cluster 1 for Brazil contains 45 members, of whom 12 are managers. Cluster 3 for the USA contains 65 members, of which 34 are managers. Cluster 2 from China contains 109, of which 24 are managers. These clusters are much less manager intensive than the managerial clusters which contain 
22 managers out of 29 for Brazil, 29 out of 36 for the USA, and 52 out of 68 for China. However compared to the two remaining clusters in each country, the managerial cluster and this secondary cluster are dominant. Only 8 managers are found in the remaining two Brazilian clusters, 17 in the remaining two US clusters, and 14 in the remaining two Chinese clusters.

Like the managerial cluster, this second cluster also shares commonalities across countries, but the similarities are not as clear as they are for the managerial cluster. Aside from dimensions upon which the managerial cluster is absolutely anomalous vis a vis its immediate colleagues and subordinates, the management cluster faces overall patterns of values which exhibit great diversity. For instance, in the Brazilian sample, cluster 2, with 39\% of the respondents, is higher than the managerial cluster (cluster 3) on virtually all four of the work quadrant dimensions, all four of the Relations quadrant dimensions, and lower than the managerial cluster on virtually all four of the Cognition dimensions. Cluster 4 of the U.S. sample, with $31 \%$ of the respondents, exhibits the exact same pattern of contrast with the North American managerial cluster (Cluster 2), as does Cluster 2 of the Chinese sample with $32 \%$ of respondents, compared to the managerial values of Cluster 1.

While these results suggest that managers across countries face some similar contextual issues, they do not support a purely convergence (Boisot \& Child, 1996; Boyer, 1996, Guillen, 2001), or universalistic (Birnbaum \& Wong, 1985; Hickson \& McMillian, 1981) view suggesting that leadership across cultures is invariant. To the contrary, the data contain all manner of interesting idiosyncrasies from one culture to the next. Space will not permit an exhaustive description and discussion of these idiosyncrasies but a few examples should be sufficient to illustrate the type and significance of the cross-cultural dynamics we discovered using the pattern approach. Consider the cluster centroids for Tolerance for Ambiguity, a variable we use as a surrogate for creativity, risk taking behavior, and flexibility. We have used bold type for the "managerial" clusters. For Brazil the centroids are: 11.53, $10.41, \mathbf{1 3 . 4 5}$ and 13.25. For the USA, they are 10.33, 13.11, 10.83, 8.52. For China, they are 12.66, 9.94, 8.50 and 9.49. If we run a simple one way ANOVA of Tolerance for Ambiguity by country, we identify a modest main effect indicating Brazil's means as highest, and China's as lowest, with the USA in the middle. By the same token, if we run a simple one way ANOVA of Tolerance for Ambiguity for managerial position, we find a modest main effect distinguishing managers from nonmanagers. However, a main effects model will not reveal that in the Brazilian sample there is a cluster containing $27 \%$ of the population with a mean Tolerance for Ambiguity identical to that of the management cluster, and that this group is low on Leadership and contains few (5 out of 44) managers. Contrast this with the Chinese sample where the mean on Tolerance for Ambiguity for the management cluster is 12.66 , and the next closest cluster mean is 9.94 .

As another example, consider the centroids for Loyalty for Brazil $(13.33,16.62,15.36,14.95)$ and China (12.21, 14.92, 14.71, 17.07). Again, the mean for the managerial cluster is bolded. The Brazilian managers work with two clusters of colleagues constituting $66 \%$ of the population $(39+27)$ who value loyalty about as much as the managerial cluster. The Chinese managerial cluster is alone in its low Loyalty scores, a full 2.5 points from its closest neighbor. The implications of these results for a manager who must implement changes in an organization are significant to say the least. In Brazil, $\mathrm{s} / \mathrm{he}$ will have a ready-made set of allies who pose no challenge to her/his leadership. In China, s/he will have no allies whose personal values support risk taking and change. Similarly, the majority of the Brazilian managers' subordinates and colleagues will view Loyalty and its rewards similarly, while the bulk of the Chinese sample will harbor personal values regarding Loyalty that are quite different from their managers. Taken together these results suggest that while managers in the three cultural settings possess important similarities in personal values, they face substantially different ecologies of personal values among their subordinates. They also suggest that in some ways, managers from these three distinct regions share more similarities with their fellow managers in other countries than with professional colleagues from their own country. The main points of our results cast in terms of differences and similarities between countries are summarized in Figure 1 below. 


\section{Similarities Across Countries}

- The managerial clusters in all three samples are high in Leadership, Abstraction, Planning and Flexibility.

- In all three countries over half of the managers are located in a small cluster comprising less than $20 \%$ of the sample.

\section{Differences Across Countries}

- China is lower than the USA and Brazil on Flexibility.

- The Brazilian managerial cluster is higher in Affect and Empathy while these variables are much lower for the Chinese and U.S. managerial clusters.

- The Brazilian managerial cluster is high in Loyalty while the Chinese and US managerial clusters are low in Loyalty.

Figure 1. Summary and Major Differences and Similarities between Brazilian, U.S., and Chinese Sample Results.

\section{Limitations and Conclusions}

Our sampling strategy in this research is limited to the white-collar portion of capitalist organizations. While clearly an important economic and social territory, the view of leadership generated by a focus on white-collar professionals omits consideration of the tensions faced by those who attempt to lead across class and technological boundaries. It is presumable that the constellation and size of our clusters would be even more extreme had we included blue-collar workers in our samples. By the same token, it is possible that at least the size of clusters and the absolute levels of certain variables would be different if public sector and NGO representatives were present in our sample. It is equally probable that because of variance in power distance and other cultural differences between the countries studied, the dynamics of the clusters identified would vary more from one culture to another if a broader sampling strategy had been used.

Our dependent variable is also limited in scope to the distinction between those occupying managerial positions; i.e. those with direct subordinates, and those without. While it seems clear that those who have secured a position which commands direct subordinates, by definition exercise leadership of some kind, this emergent leadership need be neither effective nor homogenous (A. D. S. Sant'Anna et al., 2010; Druskat \& Wheeler, 2003; Kotter, 1990). We thus can make no affirmations that the fairly robust profile of personal values that we associate with managerial incumbency is also related to leader effectiveness.

Despite these limitations and despite the exploratory nature of our research, we believe that our findings suggest interesting theoretical and practical implications that merit continuing scrutiny and investigation. Specifically:

1. Our configurational analysis of personal values reveals a robust but anomalous profile highly associated with occupancy of managerial positions across a considerable range of organizational settings in three distinct cultural environments. Those who occupy managerial positions entertain an unusual mix of values that are uncommon in the general population. For instance, they are simultaneously high in Abstraction, Planning, Organization and Flexibility. Intuition as well as our perusal of other statistically derived clusters suggest that those who emphasize Planning and Organization tend to be rather risk averse and favor stable rather than changing situations. Similarly, it is intuitive as well as easily confirmed in our results that those who are high in Abstraction tend to eschew the detail filled world of planners. Again, the managerial cluster is simultaneously attracted to big picture theories and abstractions at the same time they exhibit a tolerance for, if not interest in, more mundane planning and organization. 
2. The distinctiveness of this managerial/leadership profile is found more in the comparative levels of values in each setting than in their absolute levels. That is to say, people in our organizations find themselves in leadership positions not because they possess greater or lesser levels or certain personal values than members of our total sample, but by possessing greater or lesser levels of certain personal values than their peers. For instance, the mean in Tolerance for Ambiguity of the Chinese managerial cluster is 12.66 - lower than two of the Brazilian clusters making up more than 50 percent of the sample. It is, however, higher than any of the means for Tolerance for Ambiguity in the Chinese sample. This tournament dynamic or relative dynamic may suggest that the existence of a general managerial personality or managerial value profile that has been underestimated in studies which aggregate scores over units without adequately analyzing comparative profiles within units. It is also fraught with implications for career dynamics, training, development and selection strategies, and for the adaptation of managers who change organizational settings.

3. The size of clusters possessing certain value profiles varies considerably from one national setting to another. In some settings there are large clusters of employees with values similar to their managers. In others, the managerial cluster is comparatively small and its values quite distinct from those of the majority. These results suggest important contextual forces influencing the exercise of leadership, which to our knowledge, have not been considered in the literature.

4. Perhaps most ground breaking of all of our results, we find that the value profile associated with managerial incumbency is a somewhat rare commodity, not exceeding more than $20 \%$ in a sample of college-educated professionals in capitalist enterprises. This finding has implications for recruitment, selection, retention and training in organizations. As examples of a few intuitive implications, if this managerial type is subject to some kind of universal upper limit, managers need to be made aware that their perspective is somewhat different from the rest of the population. They may also find out that they are in a relatively privileged bargaining position vis a vis their employers. And of course our results suggest, like other trait theory research, that leadership training may add less value than careful selection and promotion.

\section{References}

Abbade, E. B., \& Brenner, F. (2009). Perfil de liderança e tomada de decisão. Revista de Administração FACES, 8(1), 107-127.

Ashkanasy, N. M., \& Roberts, E. T. (2010). Leadership in Australia: results from the GLOBE study. International Journal of Organizational Behavior, (2), 37-44.

Bass, B. M. (1985). Leadership and performance. New York: Free press.

Bass, B. M. (1998). Transformational leadership: industrial, military, and educational impact. Mahwah, NJ: Earlbaum.

Birnbaum, F. H., \& Wong, G. Y. Y. (1985). Organizational structure of multinational banks in Hong Kong from a culture-free perspective. Administrative Science Quarterly, 30(2), 262-277. doi: $10.2307 / 2393108$

Boisot, M., \& Child, J. (1996). From fiefs to clans and network capitalism: explaining China's emerging economic order. Administrative Science Quarterly, 41(4), 600-628. doi: $10.2307 / 2393869$

Boyer, R. (1996). The convergence hypothesis revisited: globalization, but still the century of nations. In S. Berger \& R. Dore (Eds.), In national diversity and global capitalism (pp. 29-59). Ithaca, NY: Cornell University Press. 
Carslyle, T. (1841). On heroes, hero worship, and the heroic in history. Boston: Adams.

Carvalho, A. M., Neto (2010). A liderança transformacional e o perfil brasileiro de liderança: entre o cru e o cozido. In R. E. Nelson \& A. S. Sant'Anna (Eds.), Liderança: entre a tradição, a modernidade e a pós-modernidade (pp. 77-94). Rio de Janeiro: Elsevier.

Carvalho, A. M., Neto, Tanure, B., Santos, C. M., \& Lima, G. S. (2012). Executivos brasileiros: na contramão do perfil deificado da liderança transformacional. Revista de Ciências da Administração, 14(32), 35-49. doi: 10.5007/2175-8077.2012v14n32p35

Carvalho, L. F., \& Vergara, S. C. (2002). A fenomenologia da pesquisa dos espaços de serviços. Revista de Administração de Empresas, 42(3), 78-91. doi: 10.1590/S0034-75902002000300008

Closs, S. J. (1996). On the factoring and interpretation of ipsative data. Journal of Occupational and Organizational Psychology, 69(1), 41-47. doi: 10.1111/j.2044-8325.1996.tb00598.x

Davel, E., \& Machado, H. V. (2001). A dinâmica entre liderança e identificação: sobre a influência consentida nas organizações contemporâneas. Revista de Administração Contemporânea, 5(3), 107-126. doi: 10.1590/S1415-65552001000300006

Derue, D. S., Nahrgang, J. D., Wellman, N., \& Humphrey, S. E. (2011). Trait and behavioral theories of leadership: an integration and meta-analytic test of their relative validity. Personnel Psychology, 64(1), 7-52. doi: 10.1111/j.1744-6570.2010.01201.x

Digman, J. M. (1990). Personality structure: emergence of the five-factor model. Annual Review of Psychology, 41(1), 417-440. doi: 10.1146/annurev.ps.41.020190.002221

Druskat, V. U., \& Wheeler, J. V. (2003). Managing from the boundary: the effective leadership of self-managing work teams. Academy of Management Journal, 46(4), 435-457. doi: $10.2307 / 30040637$

Dunlap, W. J., \& Cornwell, J. M. (1994). Factor analysis of ipsative measures. Multivariate Behavioral Research, 29(1), 115-126. doi: 10.1207/s15327906mbr2901_4

Fiedler, F. (1964). A contingency model of leadership effectiveness. In L. Berkowicz (Ed.), Advances in experimental and social psychology (pp. 301-334). New York: Academic Press.

Fonseca, A. M. O. de, Porto, J. B., \& Barroso, A. C. (2012). O efeito de valores pessoais nas atitudes perante estilos de liderança. Revista de Administração Mackenzie, 13(3), 122-149. doi: 10.1590/S1678-69712012000300007

Foti, R. J., \& Hauenstein, N. M. (2007). Pattern and variable approaches in leadership emergence and effectiveness. Journal of Applied Psychology, 92(2), 347-355. doi: 10.1037/0021-9010.922.347

Gimenez, F. A. P., \& Inácio, E., Jr. (2006). Validation of the team factors inventory in Brazilian companies. Brazilian Administration Review, 3(2), 15-31. Retrieved from http://www.scielo.br/pdf/bar/v3n2/v3n2a03.pdf. doi: 10.1590/S1807-76922006000200003

Glaser, B. G., \& Strauss, A. L. (1967). The discovery of grounded theory: strategies for qualitative research. New York: Aldine.

Grachev, M. V., \& Bobina, M. A. (2006). Russian organizational leadership: lessons from the globe study. International Journal of Leadership Studies, 1(2), 67-79.

Guillen, M. (2001). The limits of convergence. Princeton, NJ: Princeton University Press.

Hampden-Turner, C., \& Trompenars, A. (1993). The seven cultures of capitalism. New York: Currency-Doubleday. 
Hersey, P., Blanchard, K. H., \& Johnson, D. E. (1996). Management of organizational behavior (7th ed.). Upper Saddle River, NJ: Prentice-Hall.

Hickson, D., \& MacMillian, C. J. (1981). Organization and nation: the aston programme IV. Farnborough: Grower.

Hofstede, G. (1980). Culture's consequences. Beverly Hills, CA: Sage.

House, R. J. (1971). A path-goal theory of leadership effectiveness. Administrative Science Quarterly, 16(3), 321-338.

House, R. J., Hanges, P. J., Javidan, M., Dorfman, P., \& Gupta, V. (2004). Culture, leadership, and organizations: the GLOBE study of 62 Societies. Beverly Hills, CA: SAGE.

House, R., Javidan, M., Hanges, P., \& Dorfman, P. (2002). Understanding culture and implicit leadership theories across the globe: an introduction to project GLOBE. Journal of World Business, 37(1), 3-10. doi: 10.1016/S1090-9516(01)00069-4

Javidan, M., \& Carl, D. E. (2005). Leadership across cultures: a study of Canadian and Taiwanese executives. Management International Review, 45(1), 23-44.

Judge, T. A., Bono, J. E., Ilies, R., \& Gerhardt, M. W. (2002). Personality and leadership: a qualitative and quantitative review. Journal of Applied Psychology, 87(4), 765-780. doi: 10.1037/00219010.87.4.765

Keegan, J. (1987). The mask of command. New York: Viking.

Kerlinger, F., \& Lee, H. E. (2000). Foundations of behavioral research (4th ed.). Glendale, CA: Thompson Learning.

Kotter, J. P. (1990). A force for change: how leadership differs from management. New York: Free Press.

Miner, J. B. (1976). The managerial personality. Journal of Applied Psychology, 61, 419-427.

Muczyk, J. P., \& Holt, D. T. (2008). Toward a cultural contingency model of leadership. Journal of Leadership and Organization Studies, 14(4), 277-286. doi: 10.1177/1548051808315551

Nelson, R. E. (1997). Troubleshooting organizations. Westport, CT: Quorum Books.

Nelson, R. E. (2011). Adversity, Organizational culture and executive turnover in a Brazilian manufacturer. Organization Studies, 32(3), 407-425. doi: 10.1177/0170840610397479

Nelson, R. E., \& Gopalan, S. (2003). Do organizational cultures replicate national cultures? Isomorphism, rejection and reciprocal opposition in the corporate values of three countries. Organization Studies, 24(7), 1115-1151. doi: 10.1177/01708406030247006

Nelson, R. E., \& Loureiro, M. (1996). Cultura organizacional: vencendo o dragão da resistência. Rio de Janeiro: Imagem.

Nelson, R. E., Vasconcelos, E., Ponçano, V. M. L., \& Pasqualini, D. A. (2010). A subcultural analysis of the Brazilian knowledge industry: when nation, industry and organizational cultures collide. Latin American Business Review, 11(4), 317-337. doi: 10.1080/10978526.2010.536494

Ng, K. Y., Ang, S., \& Chan, K. Y. (2008). Personality and leader effectiveness: a moderated mediation model of leadership self-efficacy, job demands, and job autonomy. Journal of Applied Psychology, 93(4), 733-743. doi: 10.1037/0021-9010.93.4.733 
Oliveira, F. B. de, Sant'Anna, A. S., \& Vaz, S. L. (2010). Liderança no contexto da nova administração pública: uma análise sob a perspectiva de gestores públicos de Minas Gerais e Rio de Janeiro. Revista de Administração Pública, 44(6), 1453-1475. doi: 10.1590/S003476122010000600009

Roccas, S., Sagiv, L., Schwartz, S. H., \& Knafo, A. (2002). The big five personality factors and personal values. Personality and Social Psychology Bulletin, 28(6), 789-801. doi: $10.1177 / 0146167202289008$

Sant'Anna, A. D. S., Nelson, R. E., Campos, M. S., \& Leonel, J. N. (2010). A constructivist perspective on leadership thought among Brazilian and North American Scholars. Brazilian Administration Review, 8(2), 205-224. Retrieved from http://www.scielo.br/pdf/bar/v8n2/06.pdf doi: $10.1590 / \mathrm{S} 1807-76922011000200006$

Sant'anna, L. L., Paschoal, T., \& Gosendo, E. E. M. (2012). Bem estar no trabalho: relações com estilo de liderança e suporte para ascensão, promoção e salários. Revista de Administração Contemporânea, 16(5), 744-764. Retrieved from http://www.scielo.br/pdf/rac/v16n5/v16n5a07.pdf. doi: 10.1590/S1415-65552012000500007

Schwartz, S. H. (1999). A theory of cultural values and some implications for work. Applied Psychology, 48(1), 23-47. doi: 10.1111/j.1464-0597.1999.tb00047.x

Schwartz, S. H., \& Bardi, A. (2001). Value hierarchies across cultures: taking a similarities perspective. Journal of Cross-Cultural Psychology, 32(3), 268-290. doi: $10.1177 / 0022022101032003002$

Seltzer, J., \& Bass, B. M. (1990). Transformational leadership: beyond initiation and consideration. Journal of Management, 16(4), 693-703. doi: 10.1177/014920639001600403

Spencer, H. (1896). The principles of sociology. New York: D. Appleton.

Stogdill, R. M. (1948). Personal factors associated with leadership: a survey of the literature. Journal of Psychology, 25(1), 35-71. doi: 10.1080/00223980.1948.9917362

Tsui, A. S., Nifadhar, S., \& Ou, A. Y. (2007). Cross national, cross cultural organizational behavior research: advances, gaps and recommendations. Journal of Management, 33(3), 426-478. doi $10.1177 / 0149206307300818$

Yukul, G. A. (2006). Leadership in organizations. Upper Saddle River, NJ: Prentice Hall.

Zaccaro, S. J. (2007). Trait-based perspectives of leadership. American Psychologist, 62(1), 6-16. doi: 10.1037/0003-066X.62.1.6 